Territorios 34 / Bogotá, 2016, pp. 87-112

ISSN: 0123-8418

ISSNe: 2215-7484

La fase actual del capitalismo y la urbanización en América Latina (I)

\title{
Las heterogeneidades en la producción de la urbanización y los servicios urbanos en América Latina*
}

Heterogeneities in the Production of Urbanization, and Urban Services in Latin America

As heterogeneidades na produção da urbanização

e os serviços urbanos na América Latina

Pedro Pírez ${ }^{* *}$

Recibido: 30 de junio de 2015

Aprobado: 27 de agosto de 2015

Doi: dx.doi.org/10.12804/territ34.2016.04

Para citar este artículo

Pírez, P. (2016). Las heterogeneidades en la producción de la urbanización y los servicios urbanos en América

Latina. Territorios, 34, 87-112. Doi: dx.doi.org/10.12804/territ34.2016.04

* Una versión anterior de este articulo fue presentada en el II Seminario Internacional sobre Teoría Urbana de la Red Latinoamericana de Teoría Urbana, Medellin, febrero de 2015.

* Doctor en Derecho y Ciencias Sociales, Universidad Nacional de Córdoba (Argentina). Investigador Principal del Consejo $\mathrm{Na}$ cional de Investigaciones Cientificas y Técnicas (CONICET), en el Instituto de Estudios de América Latina y el Caribe de la Facultad de Ciencias Sociales, Universidad de Buenos Aires. Correo electrónico: ptpirez@gmail.com 
Palabras clave

América Latina, urbanización mercantil-no mercantil-desmercantilizada,

urbanización inversa, servicios urbanos.

Keywords

Latin America, commodified urbanization-not commodified urbanization-decommodified urbanization, reverse urbanization, urban services.

Palavras-chave

América Latina, urbanização mercantil-não mercantil desmercantilizada, urbanização inversa, serviços urbanos.

territarias 34

\section{RESUMEN}

Este artículo propone un esquema conceptual para estudiar los servicios urbanos como parte de la urbanización capitalista, de sus contradicciones y de los procesos estatales y sociales de desmercantilización. Intenta vincular la reproducción del capitalismo y las condiciones particulares de la población excluida del acceso al consumo por la vía mercantil, y las intervenciones estatales para enfrentar esas necesidades. Esas intervenciones estatales implican modalidades no mercantiles y desmercantilizadas, predominantemente del consumo de la urbanización. Pretende dar cuenta de la importancia de las formas no mercantiles y de desmercantilización social (producción popular del hábitat), así como de la presencia de procesos inversos de urbanización en el capitalismo dependiente de América Latina.

\section{ABSTRACT}

This article proposes a conceptual framework to study urban services as part of capitalist urbanization, its contradictions and the state and social processes of decommodification. It tries to link the reproduction of capitalism and the particular conditions of the population excluded from access to market consumption and the state interventions to address those needs: Such state interventions include non-market and decommodified terms predominantly oriented to urbanization consumption. This article seeks to explain the importance of non-market and social decommodified urbanization (popular production of habitat) as well as the presence of reverse urbanization in the dependent capitalism in Latin America.

\section{RESUMO}

Este artigo propõe um esquema conceitual para estudar os serviços urbanos como parte da urbanização capitalista, de suas contradições e dos processos estatais e sociais de desmercantilização. Tenta vincular a produção do capitalismo e as condições particulares da população excluída do acesso ao consumo pela vida mercantil, e as intervenções estatais para enfrentar essas necessidades. Essas intervenções estatais implicam modalidades não mercantis e desmercantilizadas, predominantemente do consumo da urbanização. Pretende dar conta da importância das formas não mercantis e de desmercantilização social (produção popular do hábitat) assim como da presença de processos inversos de urbanização no capitalismo dependente da América Latina. 


\section{Introducción}

El conocimiento de los servicios urbanos en las ciencias sociales de América Latina ha sido construido desde tres perspectivas que le han dado base conceptual y han colocado la temática en dependencia de un cuerpo central, diferente en cada una de ellas. Los servicios urbanos aparecen en los estudios de la urbanización como parte de los trabajos sobre la llamada 'urbanización popular'; como una aplicación de los estudios sobre la gestión urbana, particularmente en los ámbitos locales de gobierno; o bien de la reproducción social en el capitalismo de la región (Pírez, 2013a y 2013b). Ese triple origen permite un desarrollo de la temática desde perspectivas que tienden a cubrir una dimensión de los servicios urbanos como objeto de estudio (urbanización popular y gestión) y, además, en una aproximación global.

Este artículo propone un esquema conceptual de interpretación de los servicios urbanos como parte de la urbanización capitalista - mercantil-, de sus contradicciones y de los procesos estatales y sociales de desmercantilización. Intenta poner en juego las relaciones de la reproducción del capitalismo y las condiciones particulares de la población excluida del acceso al consumo por la vía mercantil, y su conexión con los procesos políticos que intervienen en esas contradicciones. Intervenciones que implican diferentes modalidades de desmercantilización, predominantemente del consumo de la urbanización. Al mismo tiempo, pretende dar cuenta, en el capita- lismo dependiente de América Latina, de la desmercantilización social que supone la producción popular del hábitat (urbanización popular). Todo ello en un juego entre solvencia e insolvencia y procesos de acceso a los bienes más allá de la insolvencia ${ }^{1}$.

Se continúan reflexiones anteriores (Pírez, 2013b) al incorporar los conceptos de mercantilización y desmercantilización, y se espera aportar elementos para el análisis de los procesos históricos de urbanización, producción de infraestructura y prestación de servicios, atendiendo al papel de los aparatos estatales y las relaciones políticas.

Se parte de una hipótesis teórico-metodológica: la comprensión de los componentes y particularidades del proceso histórico de urbanización depende de una conceptualización que permita pensar la urbanización como proceso global. Se tiene como base un concepto de urbanización capitalista que permita identificar y comprender sus componentes, para ello se identifican tres elementos: la heterogeneidad de las formas de producción y consumo, el peso de la urbanización inversa y las fuertes desigualdades. Este texto se basa en las nociones de producción mercantil y consumo mercantil, junto con producción desmercantilizada y consumo desmercantilizado de la ciudad, para identificar las condiciones particulares de la urbanización en el capitalismo dependiente de América Latina.

Los servicios urbanos son actividades económicas destinadas a producir un bien no material cuyo consumo se identifica con la actividad misma. Son componentes esenciales de la configuración y funcionamiento
${ }^{1}$ Si bien, presentamos a las condiciones de solvencia e insolvencia como si fueran polares, se trata más bien de un gradiente de capacidad monetaria. Esta suerte de dualidad analitica permite argumentar con mayor simplicidad. territarias 34 
${ }^{2}$ Se resaltan esos términosya que, como se verá, en la urbanización que caracteriza a las sociedades latinoamericanas, ese no es necesariamente el primer paso.

${ }^{3}$ Como se sabe, el suelo no es realmente un producto: no resulta de un proceso de trabajo social y, por lo tanto, no condensa valor, pero pese a ello tiene un precio y se intercambia con el resto de las mercancias como si fuera una de ellas (Jaramillo, 2010).

territarios 34 de la aglomeración urbana, que hacen parte de su capacidad de sostener a la población y las actividades allí asentadas. Estas reflexiones se focalizan en los llamados servicios de infraestructura (agua y saneamiento, electricidad y gas, fundamentalmente), $\mathrm{cu}^{-}$ ya producción y distribución se organizan colectivamente para atender necesidades que no pueden ser alcanzadas de manera individual. Son, así, valores de uso colectivo que forman parte de las condiciones estructurales del desarrollo de la ciudad capitalista (Pírez, 2013b).

En la sección 1 se introduce la urbanización capitalista como resultado de procesos mercantiles y no mercantiles de producción y consumo; en la 2 se analizan los servicios urbanos; la sección 3 estudia la urbanización de América Latina y el lugar de los servicios urbanos; la sección 4 trabaja sobre la intervención estatal y la desmercantilización social; mientras que en la sección 5 se proponen algunos elementos para una posible continuación de las indagaciones.

\section{La urbanización capitalista como resultado de la combinación de procesos de producción y consumo mercantiles y no mercantiles}

Urbanizar es poblar un espacio transformado para soportar su ocupación social aglomerada. Es habilitar una porción de la superficie de la tierra como suelo urbano: segmento espacial que puede sostener las construcciones que hacen posible la aglomeración. El primer paso $^{2}$ en la urbaniza- ción es la producción ${ }^{3}$ del suelo urbano: acondicionamiento de una o más parcelas de suelo, por decir rural, para que opere como soporte de las construcciones y, así, de la aglomeración. Parcelas que, de esta manera, son urbanizadas. Consecuentemente, el suelo urbano no es sino una porción urbanizada de la superficie de la Tierra: lotes, viviendas, infraestructuras y equipamientos, locales para actividades, etcétera. Esos componentes son condiciones de la capacidad de soportar la reproducción de la vida social aglomerada. Soportan al conjunto de las relaciones que estructuran y/o desestructuran a cada sociedad en particular, y no únicamente a su reproducción económica. Sostienen la "acumulación del capital (producción, circulación y cambio), reproducción de la población (fuerza de trabajo y no trabajo), reproducción de lo jurídico-político (política y Estado) y de lo ideológico" (Pradilla, 2013, 186).

La historia de la urbanización capitalista relaciona las fases de desarrollo con los soportes que se creen necesarios. Consideración que depende no solamente de una función técnica, que puede derivarse de las modalidades tecnológicas de producción y los soportes de infraestructura que requieren, sino de relaciones sociales, políticas e ideológicas, particularmente en lo que hace a los soportes de la reproducción de la población y de las relaciones de dominación. De la misma manera, distintas formaciones sociales capitalistas contemporáneas definen de forma diferente esas condiciones.

Esos bienes son el resultado de una pluralidad de procesos particulares de 
producción que se determinan en escenarios o ámbitos diversos (local, regional, nacional, internacional) y que están organizados, predominantemente, por actores orientados por la acumulación de capital que aplican para ello porciones del excedente económico que logran controlar. Esto es, procesos capitalistas con apropiación del plusvalor generado en la producción, que se realiza introduciendo los productos en el mercado para recibir a cambio la cantidad de recursos monetarios necesarios (o suficientes) para recuperar los costos de producción y la ganancia allí generada. Vale la pena recordar que solamente pueden apropiar y realizar esa plusvalía los agentes que disponen del capital inicial necesario para reunir las condiciones particulares de su producción y acceder a las técnicas más eficientes. Producen esos bienes de uso, esto es que se destinan a satisfacer necesidades de individuos, familias o empresas, siempre y cuando puedan ser introducidos en el mercado para obtener (en tanto bien de cambio) la cantidad monetaria que permita realizar el circuito de la acumulación.

\subsection{Mercantilización y reproducción de la fuerza de trabajo}

La población depende de su capacidad monetaria (solvencia) para acceder a los medios necesarios para su reproducción (Esping-Andersen, 1993), incluyendo las condiciones de la urbanización. Esa capacidad (solvencia) puede originarse en tres fuentes de recursos monetarios: ganancia, renta o salario ${ }^{4}$. La población no propietaria (de capitales productivos o de inmuebles) debe obtener esos recursos, sometiéndose, por un salario, a las relaciones del mercado de fuerza de trabajo, con la subordinación y los riesgos que la dinámica de dicho mercado supone: limitación del salario frente a las necesidades, dependencia de la inestabilidad de las relaciones salariales, desigualdades en la distribución de los ingresos, etcétera. Como consecuencia, ciertas familias tienen dificultades para contar con los recursos monetarios suficientes para adquirir la totalidad de los bienes que necesitan para su reproducción. En particular, los bienes urbanos dado su alto costo relativo.

La mercantilización histórica de la fuerza de trabajo supuso la eliminación, o al menos el debilitamiento, de procesos preexistentes no mercantiles que permitían la reproducción social. Algunas de esas actividades mostraron cierta persistencia $\mathrm{y}$, pese a su carácter residual, introdujeron en la reproducción de la fuerza de trabajo componentes no reconocidos en el salario (Offe, 1990; Topalov, 1979). Vale la pena considerar que de esa manera contribuyen al proceso de acumulación, al mantener bajo el valor de la fuerza de trabajo.

La mercantilización implicó la emergencia de contradicciones que contribuyeron a la configuración histórica de una reestructuración que se concretó en procesos específicos de desmercantilización a cargo, de manera predominante, del Estado como garante de la reproducción de las relaciones capitalistas (Offe, 1990). Una larga y contradictoria historia configuró ese papel que se cristaliza en el Estado de Bienestar
${ }^{4}$ En América Latina se encuentra, además, una cantidad relevante de población que se reproduce por medio de relaciones mercantiles simples, como parte de lo que se denomina 'sector informal'. territarias 34

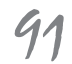


(Castells, 1995; Esping-Andersen, 1993; Offe, 1990; Topalov, 1979). Como consecuencia, el bienestar de individuos y familias no depende únicamente del circuito económico.

La desmercantilización estatal supone la capacidad (poder) político-administrativa de regulación (orientar desde fuera del mercado) del Estado y la posibilidad, contradictoria, de que esa capacidad controle las relaciones privadas de intercambio (Offe, 1990). Dos son las modalidades principales de esa desmercantilización: la exclusión de una cierta actividad económica de las relaciones de acumulación, disminuyendo las posibilidades de obtener ganancia en ella, como puede ser la gestión pública de la educación (desmercantilización de la producción) y la captación fiscal de recursos desde los ingresos sociales (renta, ganancia o salario) que se aplican a incrementar las capacidades de consumo de los grupos insolventes (desmercantilización del consumo).

Ambas operaciones implican una socialización de los costos de la reproducción de la población. En el primer caso, dado que el productor no incluye la ganancia en el costo de los productos, con lo que se configura una transferencia, en principio, en favor de los consumidores de los bienes así producidos y, en definitiva, en favor de quienes les pagan los salarios (el capital). En el segundo caso, si bien se mantienen las condiciones de la producción mercantil, y el productor recupera costos y ganancia, se transfieren recursos fiscales hacia los consumidores con el resultado de desmercantilizar, total o parcialmente, el acceso a ciertos bienes. El resultado, junto con la ampliación de ese acceso por incremento de la solvencia, es la disminución del costo de la fuerza de trabajo para sus empleadores (el capital).

En ambos casos existe transferencia de recursos vía fiscal, sea para sostener la producción sin apropiar la ganancia como para apuntalar la solvencia de los consumidores. Esa socialización se concreta por la captación fiscal de recursos monetarios y su aplicación descargando, en definitiva, los gastos de la producción y, al mismo tiempo, facilitando la reproducción de la población, sea o no fuerza de trabajo.

La significación de los procesos de desmercantilización depende del origen (ganancia, renta, salarios) de los recursos aplicados. Esto es relevante para analizar el papel redistribuidor de las intervenciones estatales: si se destinan recursos para apoyar la reproducción de los asalariados, por ejemplo, que se suman a las posibilidades de consumo de sus salarios, en lo que se ha llamado salario indirecto, este puede integrarse con recursos captados por mecanismos fiscales directos (ingresos) o indirectos (consumo) y por cotizaciones sociales.

La referencia a procesos mercantiles incluye la producción como el consumo, y la noción de desmercantilización se aplica en ambos casos. Esta distinción permite ordenar el análisis al postular la existencia de procesos de producción mercantiles o desmercantilizados, y de consumos mercantiles o desmercantilizados. Ha quedado aclarado que desmercantilizar la producción de un bien, o producirlo de manera 
no mercantil, supone excluir ese proceso productivo de las relaciones de acumulación de capital de la obtención de ganancia; desmercantilizar el consumo implica permitir su acceso, con independencia de su producción mercantil, en razón de la necesidad o de un derecho, sin contribución monetaria. Podría considerarse desmercantilización del consumo, también, si el monto monetario que se intercambia por él no está determinado por la cobertura de costos y ganancia, sino por una relación con el salario de quien lo consume.

Tal como se ha mencionado, con la práctica desaparición de formas no mercantiles, y particularmente en lo que se refiere a la producción de la urbanización, se encuentran procesos de producción y de consumo de la ciudad que se desarrollan con formas mercantiles o que, por la intervención estatal, son desmercantilizados al ampliar su cobertura social, esto es el acceso a los bienes así producidos y consumidos.

Combinando esos criterios resultan cuatro posibles situaciones conceptualmente definidas que se enuncian en la siguiente tabla.

Tabla 1. Producción-Consumo / MercantilDesmercantilizada

\begin{tabular}{|l|l|c|c|}
\hline \multicolumn{2}{|c|}{} & \multicolumn{2}{c|}{ Consumo } \\
\cline { 3 - 4 } \multicolumn{2}{|c|}{} & Mercantil & $\begin{array}{c}\text { Desmercanti- } \\
\text { lizado }\end{array}$ \\
\hline \multirow{2}{*}{$\begin{array}{l}\text { Produc- } \\
\text { ción }\end{array}$} & \begin{tabular}{l} 
Mercantil \\
\cline { 2 - 4 }
\end{tabular} & 1 & 2 \\
\hline
\end{tabular}

Fuente: elaboración propia.
La situación 1 es el caso predominante. Se produce aquello que tiene demanda solvente: se orienta a satisfacer una necesidad (bien de uso) en la medida que, siendo introducido en el mercado, recibirá a cambio una cantidad de dinero que, además de recuperar los costos, permitirá realizar la ganancia (bien de cambio). En la situación 2 se encuentra la aplicación de procesos de desmercantilización del consumo manteniendo su producción capitalista. Se facilita el acceso a la urbanización de manera independiente de las condiciones económicas de los individuos o familias, cuando entre el productor capitalista y el consumidor interviene algún mecanismo ajeno al mercado que hace posible la remuneración del capital, y la obtención de ganancia, y, a la vez, el acceso al bien por parte de individuos o familias sin que entreguen recursos monetarios para ello. El Estado asume costos monetarios que garantizan la producción capitalista y, así, permite el acceso a esos bienes como resultado del reconocimiento de un derecho. La situación 3 refiere a casos de apoyo estatal a la producción para su desmercantilización total o parcial que son introducidos al mercado formal. La situación 4 indica el consumo desmercantilizado de bienes producidos de igual manera que así son accedidos por la población sin realizar una contraprestación monetaria.

\section{Los servicios urbanos y la urbanización}

Los servicios urbanos son un componente de la urbanización: actividades económicas 
${ }^{5}$ Básicamente, en términos económicos, técnicos y ambientales.

${ }^{6}$ Además de estos, convencionalmente se mencionan los servicios urbanos de mantenimiento y los de transporte.

territarios 34 que producen bienes no materiales que integran la capacidad de la ciudad para sostener a la población y las actividades (Pírez, 2013 b), en tanto que resuelven, de manera colectiva, necesidades que no pueden ser encaradas individualmente, o cuya atención individual sería poco racional $^{5}$ (provisión de agua, energía, transporte y comunicaciones, recolección y disposición de residuos, etc.) (Cuervo 1988). Son necesarios para la reproducción de la acumulación de capital, en sentido estricto, como para la reproducción de la población, sea o no fuerza de trabajo, como para la legitimidad de las relaciones sociales (Jaramillo, 1988; Pradilla, 2009).

Se hace referencia, de manera particular, a los servicios urbanos de infraestructura ${ }^{6}$, que se basan en un soporte material (infraestructura propiamente tal) para poner a la disposición (proveer) de los habitantes urbanos un bien de uso determinado: agua, saneamiento, electricidad, movilidad, etcétera. La infraestructura es el conjunto de las construcciones que soportan la configuración y el funcionamiento de los servicios y, así de las ciudades, posibilitando el uso del territorio urbano: redes que conducen y distribuyen esos bienes y servicios fundamentales para la urbanización.

La inclusión de la población en el uso de los servicios urbanos es una condición (necesaria pero no suficiente) de su inserción en la ciudad y de su participación en la distribución de los bienes sociales (Pírez, 2009). Esos servicios son una posibilidad de integración del conjunto de los habitantes en la aglomeración urbana, "en la vida social y política, donde se acumulan no solo las riquezas, sino conocimientos, técnicas y obras (obras de arte, monumentos)" (Lefebvre, 1969, p. 18).

Como soportes materiales de la urbanización, los servicios de urbanización integran las condiciones generales de la reproducción de la sociedad urbana, lo que sustenta la cooperación fuera del taller por la interdependencia de los capitales individuales que amplían la división del trabajo hacia el conjunto de la sociedad. Esta socialización depende de las leyes externas del mercado y ocurre de forma precaria y contradictoria.

Como condiciones generales, los servicios urbanos son valores de uso indispensables para la acumulación. Sin embargo, los capitales individuales difícilmente pueden producirlos. Esto se debe, entre otros factores, a la gran escala necesaria, a la dificultad para dividir el consumo colectivo, a la falta de demanda solvente y al largo período de rotación del capital. La producción capitalista de esos bienes, con una tasa de ganancia individual adecuada, haría imposible su papel y pondría en cuestión "la tasa de ganancia global” (Jaramillo, 1988). En el capitalismo avanzado, como se vio, esas contradicciones han sido enfrentadas con procesos de desmercantilización por medio de la intervención estatal (Offe, 1990), que sobre la base de la generalización de la relación salarial (Castel, 1997), consolidaron los mecanismos propios del Estado de Bienestar. 


\section{La urbanización dependiente de América Latina y los servicios urbanos}

La urbanización en América Latina se originó con la incorporación de sus sociedades en la división internacional del trabajo, como oferentes de bienes primarios para la industrialización en otros territorios. En ese contexto, la subordinación de los procesos locales de acumulación de capital, con la transferencia a las economías centrales de parte del excedente, frena el desarrollo de las fuerzas productivas y limita el dinamismo económico local. Una importante cantidad de población queda fuera del mercado de fuerza de trabajo, o se inserta en él en forma precaria y contribuye a mantener bajos los salarios. En estas sociedades se exacerban las limitaciones del consumo mercantil, quedando fuera de las posibilidades de acceso monetario (solvencia) proporciones muy importantes de población.

Los aparatos estatales se caracterizan por su débil intervención, coherente con las condiciones de la acumulación capitalista subordinada y la consecuente "limitación relativa de los recursos que la formación social como un todo puede destinar a la creación de estas condiciones generales de la acumulación, y en particular, a los valores de uso colectivo urbanos" (Jaramillo, 1988, p. 28). Esos recursos se asignan predominantemente para crear "valores de uso directamente ligados a la acumulación de capital, y en particular a la producción de mercancías, en detrimento de aquellos ligados con el consumo y, especialmente, con la reconstitución de las capas populares" (Jaramillo, 1988).

De todas formas, los estados de esas sociedades intervinieron con intentos de responder a las necesidades de la acumulación económica y al fortalecimiento de la legitimidad política, lo que le garantiza a los trabajadores, y aún a la población no incluida en relaciones salariales, cierto nivel en las condiciones materiales de subsistencia (Bonduki, 201 1; Pradilla, 2009; Yujnosky, 1984;). Pese a esas intervenciones, especialmente entre los años cuarenta y ochenta del siglo $\mathrm{xx}$, no se logró disminuir el peso de la exclusión mercantil ni se institucionalizó una situación de 'estado de bienestar', más allá de cierta y limitada 'democratización del bienestar' (Torre \& Pastoriza, 2002). Ese fue el contexto del fuerte crecimiento demográfico urbano, en especial entre 1940 y 1970, que determinó la magnitud de la exclusión social urbana.

Consecuentemente, los estados descansaron sobre el esfuerzo de los sectores populares para la provisión de algunos de esos bienes (Jaramillo 1988), en situaciones muchas veces caracterizadas por el predominio de relaciones políticas de carácter clientelar (Duahu, 1998; Hayata, 2010).

\subsection{La urbanización en América Latina}

La urbanización latinoamericana puede ser caracterizada por tres rasgos principales: la heterogeneidad de las formas de su producción y consumo, los procesos de 
urbanización inversa y las fuertes desigualdades en los territorios urbanos.

Se dice heterogeneidad dado que, junto con las formas mercantiles y estatalmente desmercantilizadas propias del capitalismo avanzado, se encuentran procesos mercantiles simples, no mercantiles y de desmercantilización social, tanto en la producción como en el consumo.

La tabla 2 menciona esas posibilidades e indica situaciones lógicas que no siempre son históricas.

Tabla 2. América Latina: diferentes modalidades de producción-consumo de la urbanización

\begin{tabular}{|l|c|c|c|c|}
\hline \multirow{2}{*}{ Producción } & \multicolumn{4}{|c|}{ Consumo } \\
\cline { 2 - 5 } & $\begin{array}{c}\text { Mer- } \\
\text { cantil }\end{array}$ & $\begin{array}{c}\text { No } \\
\text { mer- } \\
\text { cantil }\end{array}$ & Desmercantilizado \\
\cline { 3 - 5 } & 1 & 2 & 3 & 4 \\
\hline Mercantil & 5 & 6 & 7 & 8 \\
\hline $\begin{array}{l}\text { Mercantil } \\
\text { Simple }\end{array}$ & 9 & 10 & 11 & 12 \\
\hline No mercantil & 13 & 14 & 15 & 16 \\
\hline $\begin{array}{l}\text { Desmercantiliza- } \\
\text { da estatal }\end{array}$ & 17 & 18 & 19 & 20 \\
\hline $\begin{array}{l}\text { Desmercantiliza- } \\
\text { da social }\end{array}$ & 19 & & \\
\hline
\end{tabular}

Fuente: elaboración propia.

La situación 1 muestra el caso predominante, de manera análoga a esa situación en la tabla 1. El consumo de los bienes producidos mercantilmente puede darse sin que los consumidores dispongan de los recursos monetarios necesarios, en las situaciones de desmercantilización del consumo que aparecen indicadas como 3 y 4 en la tabla 2. Junto con los procesos estatales de desmercantilización, y en gran medida debido a su debilidad y/o limitación, se encuentran situaciones de desmercantilización social (4): bienes de la urbanización producidos mercantilmente son accedidos porque se elimina o disminuye la necesidad de dinero, pero no por una intervención estatal, sino por procesos organizados de manera autónoma por individuos, familias o grupos de sectores populares. Al no existir transferencias financieras estatales no hay redistribución: los consumidores no solventes asumen la carga no solo de aportar su trabajo, sino a veces también recursos financieros. Se configura una situación de expoliación urbana, como la definiera Lucio Kowarick (1979).

La situación 2 refiere al consumo no mercantil de un bien mercantilmente producido. Esto ocurre en los casos de ocupaciones de hecho (invasiones) de suelo o vivienda, o con el uso clandestino de infraestructuras y/o servicios urbanos mercantiles. Esos consumos suponen una posible contradicción con el derecho de propiedad, que los lleva a ser caracterizados como clandestinos o ilegales y, en algunos casos, como delitos. Se utiliza el potencial porque en ciertas condiciones la ocupación de una propiedad inmueble, por ejemplo, puede dar lugar a la creación de un derecho, cuando se constituye en un antecedente para adquirir institucionalmente el bien por el paso de tiempo, en situaciones de usucapión.

Una situación particular de producción mercantil, la mercantil simple, se concreta

\section{territarios 34}


por medio de consumos mercantiles (5), con la necesidad de aportar la cantidad de recursos monetarios que responde al cálculo económico del productor, de manera análoga a lo que sucede con la producción plenamente mercantil (1). Igualmente, podría ser consumida con base en alguna desmercantilización estatal (7), por ejemplo con un crédito subsidiado o por medio de una desmercantilización social (8). Un consumo no mercantil, por ejemplo, la ocupación de una vivienda construida por un productor mercantil simple (6), sería análogo a la misma situación de una producción plenamente mercantil (2).

Junto con las formas mercantiles, en las ciudades latinoamericanas aparece una fuerte presencia de modalidades no mercantiles, tanto de producción como de consumo. Se trata de producción de la urbanización (suelo, vivienda, infraestructuras, etc.), que se realiza para satisfacer la necesidad de esos bienes sin orientarse a la obtención de ganancia y sin incorporarse, por lo tanto, en el mercado. Esa producción supone un consumo correlativo, por lo que no requiere aportar recursos monetarios (10). Dos son las modalidades fundamentales, producción estatal no mercantil, con una presencia muy pequeña en las sociedades latinoamericanas y producción popular del hábitat ${ }^{7}$ responsable de cerca de la mitad de esas ciudades. Esta última es parte de "las prácticas de hacer ciudad que efectúan los mismos pobladores empobrecidos [...]" (Jaramillo, 2012, p. 33), que se orientan por una lógica de necesidad (Pírez, 1995).
En la tabla 2 muestra otras situaciones. Producción no mercantil y consumo mercantil. La concreción más común aquí es la posterior introducción del bien urbano en el mercado: el autoconstructor popular puede introducir esa vivienda en el mercado informal, sea en venta o alquiler (Abramo 2012, Cravino, 2006). Un caso particular se configura cuando se retira del mercado un bien por su ocupación (2) y, en un segundo momento, a partir de esta nueva situación no mercantil, es mercantilizado por ese primer ocupante para permitir otros usos por medio del pago de una cantidad determinada de dinero.

La producción no mercantil mercantilizada podría ser consumida con base en algún mecanismo estatal que le permita adquirir solvencia (7), siempre que las condiciones formales lo permitan. Con la desmercantilización social (8) es posible el acceso al consumo mercantilizado con el apoyo para incrementar la solvencia por fuera de los procesos estatales.

La urbanización puede ser producida con base en el apoyo estatal desmercantilizador (en el financiamiento, el costo de los materiales, exenciones impositivas, etc.) para ser introducido de manera plena al mercado (13). Esa transferencia estatal podría tener dos efectos diferentes. Por un lado, el productor podría beneficiarse totalmente con ese apoyo, vendiendo en el mercado los bienes al precio "normal", captando de esa manera una sobreganancia. Por otro lado, la disminución de los costos de la producción por la desmercantilización estatal podría reflejarse en un precio menor
Para un excelente trabajo sobre ese tema, ver Connolly, 2013. territarios 34 
${ }^{8}$ Esto es, un área de urbanización plena.

${ }^{9}$ Se dice urbanización, sin adjetivar, para indicar los procesos de producción del espacio urbano que se han convertido en una suerte de modelo de la ciudad capitalista, particularmente a partir de las condiciones de Estado de Bienestar. La intención es, justamente, mostrar la particularidad de esas situaciones en el capitalismo de las sociedades latinoamericanas.

\section{territarios 34} 98 que en la producción meramente mercantil, consumiéndose esos bienes con un esfuerzo monetario correlativamente menor, que no afectaría la ganancia del productor mercantil, garantizada por la transferencia desmercantilizadora.

El consumo de ese bien podría ser también el resultado de un proceso estatal de desmercantilización (15), lo que disminuye, por ejemplo, los costos financieros de la operación, o bien de alguna desmercantilización social (16).

Si la desmercantilización de la producción es social, el productor obtiene, de apoyos familiares o comunitarios, recursos financieros o mejores costos en los materiales para sostener la producción de una vivienda, que luego es introducida en el mercado (17). En este caso se dan las mismas situaciones: si el bien es introducido a precios del mercado, el productor tendría sobre ganancias a costa de quienes contribuyeron a la disminución de sus costos, si el bien es introducido con precios menores gracias a la desmercantilización social, sería de adquisición menos pesada en términos monetarios. Ese consumo, por su parte, podría estar apoyado en algún proceso estatal de desmercantilización (19), siendo el más común, el crédito subsidiado, o bien el comprador podría basarse en el apoyo familiar o comunitario (20). Es también lógicamente posible el consumo no mercantil de la urbanización producida en casos de desmercantilización estatal (14) o social (18).

Vale la pena recordar que los procesos no mercantiles como de desmercantilización social existentes en las ciudades de América Latina no constituyen un fenómeno residual, sino que se trata de casos persistentes que representan a la mitad de la ciudad producida.

El segundo rasgo que se ha mencionado, la urbanización inversa, indica la ocupación de la población de una porción de tierra que no cuenta con las condiciones de la urbanización, o muestra una gran deficiencia de ellas, estando integrada física $\mathrm{y}$ funcionalmente a una ciudad preexisten$\mathrm{te}^{8}$. Es inversa porque, paradójicamente, se trata de la ocupación de suelo urbano sin urbanización. Vale la pena ser redundante, es un caso de suelo urbano no urbanizado.

En la urbanización ${ }^{9}$, la población llega luego de que el lugar haya sido urbanizado. Esa secuencia permite a sus ocupantes la reproducción social familiar en sentido amplio, en la medida que ofrece suelo, vivienda, infraestructuras y servicios, por lo menos en un mínimo de cantidad y calidad.

En la urbanización inversa, por el contrario, la población llega antes de que se produzcan sus condiciones, o de que esa producción sea suficiente para garantizar la reproducción de la vida social aglomerada: es la "modalidad de urbanización en la que primero se habita y luego se urbaniza" (Castro \& Riofrío, 1997, p. 45).

Esa urbanización es inversa no solamente en relación con un modelo, sino con una urbanización preexistente en la misma ciudad. No se trata exclusivamente de la expansión territorial hacia áreas vacías, sino de la ocupación de suelo no servido, o por lo menos no servido en su totalidad, dentro 
de las ciudades servidas. Podría darse una urbanización inversa tanto en las periferias urbanas como en las áreas centrales (favelas o villas).

No debe confundirse la distinción anterior con la diferenciación regular/irregular. Se encuentran situaciones de urbanización inversa sin irregularidad cuando no existen normas que establecen esa secuencia, es decir cuando es posible la ocupación regular del suelo sin que se hayan producido, previamente, las condiciones mínimas de habitabilidad urbana. Si bien, lo que se remarca es la secuencia del proceso, es evidente que tal secuencia suele estar marcada por la normativa. De allí que se encuentren dos modalidades de urbanización inversa: regular cuando tal normativa no existe y no regular cuando la normativa existe y no es cumplida. En ambos casos, si la urbanización se completa es un resultado que depende de la capacidad de las familias ocupantes de resolverla de manera mercantil o no.

Tampoco debe confundirse urbanización inversa con la insolvencia. Más allá de que, como es conocido, esa modalidad de urbanización corresponda casi totalmente en términos históricos con los procesos de asentamiento urbano de la población que está excluida del acceso mercantil formal por la falta de recursos. En un nivel de análisis más general, se puede entender que el ordenamiento de la urbanización en las sociedades latinoamericanas incluye esas dos modalidades. Ambas constituyen un desenvolvimiento del orden urbano en el sentido de la aplicación que realiza
Connolly (2012) de la formulación de Duhau y Giglia (2008). Ambas modalidades - juntas, coexistentes - definen ese orden urbano.

Las desigualdades de las urbanizaciones latinoamericanas constituyen su tercer rasgo distintivo. De lo antes dicho se deriva de manera inmediata una primera diferenciación entre urbanización y la que a ella se integra como urbanización inversa. Una servida y la otra no, pero que se va completando con el paso del tiempo. El resultado es la existencia de ámbitos urbanos de muy diferentes y desiguales condiciones $\mathrm{y}$, por ende, de vida urbana: calidad y cantidad de suelo, de vivienda, de infraestructuras, equipamientos y servicios, de condiciones ambientales, etc. Se puede asegurar que el predominio de las formas mercantiles de producción y consumo de la ciudad en las sociedades latinoamericanas es el factor de esa alta desigualdad.

Las ciudades de la región, por lo menos desde el inicio de los procesos de industrialización por sustitución de importaciones, en general desde los años cuarenta del siglo $\mathrm{XX}$, son el resultado de esas dos modalidades simultáneas, interrelacionadas y persistentes de urbanización. Esta simultaneidad y persistencia sugiere que se mantienen estructuralmente, en forma independiente a los procesos de crecimiento económico y de mejora de los demás indicadores sociales (Jaramillo, 2012). Persistencia que ha permitido la consolidación de las diferencias y desigualdades en las ciudades latinoamericanas. 
${ }^{10}$ Esta presentación simplificada no incluye la distribución de las rentas del suelo (Jaramillo, 2010).

territarias 34

\subsubsection{Urbanización y servicios urbanos}

Las ciudades latinoamericanas presentan una doble modalidad de urbanización, los servicios urbanos, como componentes de esa urbanización, muestran también esas dos modalidades de producción, consumo y gestión. Junto con la urbanización, por lo general mercantil y sujeta a las normas jurídicas, se encuentran áreas cuyos servicios, si existen, han sido producidos predominantemente luego de la ocupación del suelo, sea en procesos mercantiles o no (tabla 3 ).

Tabla 3. Urbanización y urbanización inversa: producción mercantil y no mercantil

\begin{tabular}{|l|c|c|}
\hline & \multicolumn{2}{|c|}{$\begin{array}{c}\text { Completamiento } \\
\text { de la urbanización }\end{array}$} \\
\hline Modalidad & Mercantil & No mercantil \\
\hline Urbanización & 1 & 3 \\
\hline Urbanización inversa & 2 & 4 \\
\hline
\end{tabular}

Fuente: elaboración propia.

En la urbanización, quien produce sus componentes, sea el desarrollador o promotor (Schteingart, 1989), es responsable tanto de la disponibilidad de suelo como de las construcciones que lo habilitan, cuya cantidad y calidad depende de las regulaciones existentes. Esas normas, por lo general, introducen una particular orientación socioeconómica a los procesos de urbanización: las superficies mínimas de los lotes, la superficie destinada a usos públicos, así como la cantidad y calidad de las infraestructuras, servicios y equipamientos obligatorios implican claramente una particular orientación en tal sentido. La configuración segregada de la ciudad es, en parte, un resultado de esas normas.

Los procesos de urbanización se han desarrollado tanto por medio del predominio de modalidades mercantiles como desmercantilizadas. A continuación se verán cada una de ellas.

\subsection{La urbanización mercantil}

El desarrollador mercantil produce los componentes de la urbanización, para lo cual necesita conseguir financiamiento y contratar (si no lo hace por sí mismo) las operaciones particulares de construcción de la infraestructura: vialidades, redes de agua y saneamiento, redes de electricidad y demás, según esté legalmente obligado, y de la vivienda si es el caso. Con la venta del suelo, o de las viviendas, recuperará los costos de producción (que incluyen los del financiamiento), así como la ganancia en cada una de sus fases ${ }^{10}$. El acceso al suelo para construir la vivienda, o directamente a la vivienda ya construida, pone a sus adquirentes en condiciones de gozar por completo del proceso de urbanización; para ello pagan el precio acordado. Esa completitud implica, además de la disponibilidad de las infraestructuras, que los servicios sean prestados.

Los compradores adquieren un ámbito urbano (hábitat) que permite la vida social, pues satisface la necesidad de bienes que la sostienen: suelo, vivienda, agua y saneamiento, electricidad, gas, transporte, etc. El costo monetario de la producción de la in- 
fraestructura de los servicios queda incluido en la carga económica de los adquirentes de la vivienda. Luego, con la conexión, las tarifas que paguen los residentes permiten la provisión mercantil de dichos servicios.

Esa breve y esquemática descripción permite identificar los actores fundamentales en esta modalidad de urbanización ${ }^{11}$, incluyendo los servicios: el desarrollador de la urbanización, quienes financian su producción, los constructores de los bienes físicos de su habilitación (infraestructuras, equipamientos, etc.), los prestadores de los servicios que utilizan las infraestructuras, los compradores del producto final, y quienes financian esa compra. Todas las operaciones que llevan a cabo esos actores, y sus vinculaciones, se sostienen económicamente con el aporte monetario de los compradores-residentes en la urbanización.

\subsection{La urbanización desmercantilizada}

Esta forma de la urbanización es el resultado de varios procesos, generalmente parciales, de desmercantilización que tienden a sostener $^{12}$ la solvencia de los adquirentes. Se han aplicado subsidios para disminuir los costos de la producción mercantil, como para apoyar la solvencia de los consumidores.

Los subsidios financieros de los estados transfieren a los adquirentes parte de los recursos monetarios necesarios para acceder mercantilmente a la urbanización, normalmente por medio de la disminución del costo y las condiciones del financiamiento. En general, en América Latina esto ha sido realizado por medio de bancos hipotecarios (públicos o privados) o utilizando fondos para ser aplicados a ese financiamiento (INFONAVIT, FONAVI, etc.) (Coulomb \& Schteingart, 2006; Bonduki, 201 1; Jaramillo, 1981; Puebla, 2002 y 2006; Yujnovsky, 1984). De manera particular en la Argentina, específicamente en el Área Metropolitana de Buenos Aires ${ }^{13}$ (AMBA), el crédito subsidiado estuvo a cargo principalmente del Banco Hipotecario Nacional (BHN), que durante la expansión metropolitana entre los años cuarenta y setenta fue muy importante (Yujnovsky,1984) para fortalecer la solvencia de los pobladores. Luego de que el BHN perdiera relevancia, ese apoyo continuó por medio de los programas del FONAVI $^{14} \mathrm{y}$, últimamente, los Planes Federales y el PROCREAR ${ }^{15}$ (Cravino, 2012). El apoyo financiero a la demanda fue utilizado en prácticamente todos los países de la región, a cargo de diferentes organismos bancarios, normalmente de propiedad estatal, o con recursos provistos de manera subsidiada desde fondos fiscales (Bonduki, 2011; Jaramillo, 1981; Yujnovsky, 1984).

También se encontró, con menor frecuencia aunque a veces con mayor relevancia, procedimientos de oferta desmercantilizada de suelo ${ }^{16}$, así como el control del precio de los materiales.

Por último, puede ser relevante el subsidio estatal a los transportes que facilitan la ocupación de suelo cada vez más lejano de las áreas centrales. Es el caso de la ocupación del AMBA por parte de sectores medios y bajos en las décadas de 1940 y 1950; la nacionalización de los ferrocarriles permitió subsidiar las tarifas metropolitanas, a lo
11 Solamente se mencionan estos actores de manera agregada. Ver Jaramillo (1981) y Schteingart (1989).

12 Se utiliza ese término, claramente difuso, para indicar situaciones por medio de las cuales se les facilita a los usuarios relativamente solventes la adquisición de un lugar en la urbanización mercantil.

13 Se trata del territorio metropolitano configurado a partir de la ciudad de Buenos Aires y que integra además a 24 municipios de la provincia de Buenos Aires. Con una superficie de $3833 \mathrm{~km}^{2}$ tenía 12801364 habitantes en el año 2010.

${ }^{14}$ Desde 1972.

${ }_{15}$ Ya a inicios de los años 2000.

${ }^{16}$ No se desarrolla este aspecto.

territorias 34

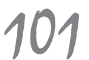


${ }^{17}$ Ver Pírez (2014).

${ }^{18}$ No toda adquisición por loteo pirata se realiza por compradores insolventes.

territarios 34 que se sumó el subsidio a los autobuses que complementaban las comunicaciones con los ferrocarriles. Esos subsidios facilitaron la realización mercantil del suelo.

Una situación particular, que también puede ser calificada como desmercantilización por la disminución del costo del financiamiento, es la de los llamados 'conjuntos urbanos’ en México, así como su antecedente, la política de vivienda aplicada en Chile desde la dictadura (Eibenschutz \& Goya, 2009; Rodríguez \& Sugranyes, 2005), y las políticas desarrolladas en Brasil (' minha vida minha casa') y alguno de los planes federales en la Argentina (Cravino, 2012). Si bien, esta situación amerita mayor análisis, no es este el lugar ${ }^{17}$.

Si se pregunta sobre la naturaleza de la urbanización subsidiada, es posible suponer que la intervención del Estado facilita, o aporta condiciones, para su realización mercantil. La aplicación de los subsidios mejora las condiciones de solvencia de algunos sectores de la población (medios o medios bajos) y les permite operar en el mercado inmobiliario. Se trata de operaciones organizadas para la valorización de los capitales individuales que se aplican a la producción de los diferentes componentes de la urbanización. Más allá de que puedan estar a cargo de un promotor privado o estatal. La cuestión relevante es la capacidad de cobertura socioeconómica de esas experiencias.

\subsection{La urbanización inversa}

En la urbanización inversa, los procesos, actores y resultados son diferentes. El com- pletamiento de la urbanización, que se produce luego del acceso al lote, queda a cargo de los adquirentes y, como se ha indicado, puede ser realizado por medios mercantiles o no mercantiles. También se mencionó que no existe correlación entre urbanización inversa y población insolvente.

En esta modalidad, el suelo (no urbanizado) es adquirido por medios legales o no legales. La primera situación, poco común, se da cuando se vende suelo sin que existan normas que obliguen a su urbanización previa, como fue el caso de la expansión de la ciudad de Buenos Aires sobre los municipios de la provincia de Buenos Aires hasta 1977. La segunda, predominante en este tipo de procesos, por la ocupación clandestina de la tierra (invasión) o cuando los lotes son comprados en operaciones ilegales, en los llamados loteos piratas ${ }^{18}$.

\subsection{La urbanización inversa mercantil}

Esta modalidad supone, obviamente, la solvencia de los pobladores. Estas operaciones no suelen estar a cargo de un promotor. Por lo general, son procesos individuales en la producción de la vivienda, normalmente por encargo (Jaramillo 1981). Pero esa modalidad se ve imposibilitada para producir la infraestructura, los equipamientos y la prestación de los servicios. Se encuentran, por ello, procesos colectivos que vinculan a los residentes con productores mercantiles de esos bienes.

Antes de analizar la producción de las infraestructuras conviene diferenciar las infraestructuras destinadas a sostener el 
desarrollo de las actividades económicas, la reproducción del capital, de aquellas destinadas a la reproducción de la población, fuerza de trabajo o no. Es difícil establecer claramente esa distinción, ya que los servicios de infraestructura están sistémicamente integrados, pero es posible identificar la infraestructura barrial que sustenta los servicios destinados de manera directa a la población, y diferenciarla de la infraestructura troncal, que alimenta a la totalidad del sistema, junto con la infraestructura destinada a las actividades económicas, particularmente a la industria. Esta última es, por lo general, el resultado de planes estatales con financiamiento propio o con recursos del crédito de organismos internacionales (socialización) (Pírez, 2000), mientras que las infraestructuras barriales, solamente posibles de utilizar si existen las redes troncales con cercanía a los loteos, son financiadas por los residentes.

Es necesario que los pobladores se organicen para encargar a alguna empresa la construcción de las infraestructuras. El Estado puede estar presente facilitando la operación mercantil, es el caso de las obras públicas municipales de infraestructura urbana en el AMBA que, según la Ordenanza General 165 (1973), deben ser pagadas por los "propietarios o poseedores a título de dueño" de los "inmuebles beneficiados". Esos vecinos contratan con las empresas constructoras (privadas o públicas) a quienes pagan en cuotas el costo de las obras, desde un monto total calculado a partir del precio al contado, que se prorratea entre los vecinos en razón de la extensión lineal de los frentes ${ }^{19}$ de sus lotes; de su superficie; o de la razón entre frente y superficie. El pago total no podrá exceder el $33 \%$ del valor real del inmueble con la mejora incorporada ${ }^{20}$. Si las obras se realizan por contrato directo o por licitación con empresas privadas deben ser respaldadas por el $70 \%$ de los propietarios. Si ello sucede, se convierten en obligatorias para todos los vecinos que se benefician con ellas. Se producen así, por ejemplo, pavimentos, redes de agua y saneamiento y de gas. Una vez producida la infraestructura, esta es transferida a la unidad de producción ${ }^{21}$ del servicio particular para que los 'frentistas' sean incorporados a su prestación. La transferencia de la infraestructura barrial, su conexión con la troncal y el comienzo de la prestación del servicio se da en la medida que los residentes establecen una relación mercantil individual con el prestador de cada servicio ${ }^{22}$.

\subsection{La urbanización inversa no mercantil}

Conseguido el acceso al suelo, operación nada sencilla, comienza la producción del medio urbano. Aquí debe diferenciarse la construcción de la vivienda y de las infraestructuras, equipamientos y servicios. La autoconstrucción de vivienda ha sido suficientemente atendida en la literatura sobre urbanización popular ${ }^{23}$. No es así con las infraestructuras y los servicios. En esta situación se encuentran procesos de desmercantilización estatal como no estatal. Vale la pena aclarar que se trata de la producción de infraestructura barrial, que
${ }^{19}$ De allí que en estas operaciones se hable de los 'frentistas'.

${ }^{20}$ Se introduce una noción cercana a la de contribución por mejoras.

${ }^{21}$ Sea esta una empresa privada capitalista o un organismo estatal.

${ }^{22}$ Un análisis más preciso debe diferenciar el control de las infraestructuras (troncales y barriales) y de la prestación de los servicios por parte de empresas privadas capitalistas o estatales.

${ }^{23}$ Puede consultarse entre otros: Azuela y Schteingart (1990), Dubau (1998), Connolly (2013).

territarias 34

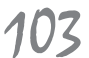


${ }^{24}$ Como sucedia con lasempresas estatales de servicios urbanos en el AMBA hasta su privatización en los años noventa del siglo pasado.

${ }^{25}$ Consistentes en aporte de maquinarias, algunos materiales y dirección técnica, por ejemplo.

territarios 34 depende de la existencia de infraestructura troncal cercana o ya puesta en operación, igualmente cercana.

En la urbanización inversa no mercantil la modalidad de tenencia del suelo suele arrastrar su calificación hacia la posterior urbanización. Por eso mismo, podría suponerse que en un caso de acceso regular a suelo no urbanizado, la población ocupante, que no logra acceder al mercado de vivienda y demás componentes de la urbanización ni se beneficia de programas estatales para ello, producirá por sí misma esos bienes necesarios para la vida urbana. Por otro lado, la ocupación irregular del suelo suele impedir la producción mercantil, en la medida que en algunos casos, al menos, se exige una tenencia regular para acceder a los servicios ${ }^{24}$.

Antes de continuar es preciso aclarar que la capacidad de producir infraestructura por medio de procedimientos no mercantiles está limitada por dos aspectos centrales: la capacidad de inversión y de acceso a las tecnologías adecuadas a ciertas infraestructuras. Como resultado, será posible producir infraestructuras relativamente elementales y que abarquen áreas reducidas. Suele tratarse, consecuentemente, de redes domiciliaras de distribución a partir de conexiones, por lo general clandestinas, desde redes trocales o secundarias cercanas a los asentamientos. Esto es, la conexión con las redes de distribución eléctrica de bajo voltaje, o con las redes de distribución de agua.

Es evidente la limitación que tiene esta producción de los componentes infraestructurales de la urbanización. De allí que se encuentren situaciones de apoyo estatal para esos casos, los que permiten identificar una sub-situación: urbanización inversa no mercantil con desmercantilización social apoyada estatalmente. En el AMBA existen varios casos, más o menos institucionalizados, de políticas que facilitan la producción socialmente desmercantilizada de infraestructura, en especial de las redes de agua. Desde apoyo municipal ${ }^{25}$ a barrios que autoconstruyen sus redes domiciliarias, hasta programas del gobierno federal que, organizando a los productores en cooperativas, aporta el financiamiento necesario para la construcción de redes de agua y drenaje sanitario.

\section{La intervención del Estado en la urbanización en América Latina: la emergencia de la desmercantilización social y sus límites}

Los apartados anteriores muestran la importancia del papel de los estados latinoamericanos en la urbanización y, particularmente, en la producción y gestión de los servicios urbanos.

Tal intervención no es una mera respuesta "estructural", sino que se da dentro de un conjunto de condiciones, como son, entre otras, la relevancia del excedente de mano de obra en cada sociedad y en diferentes momentos; la existencia de prácticas no mercantiles de reproducción de la fuerza de trabajo; las luchas sociales entre el trabajo y el capital relativas a la reproducción de la fuerza de trabajo, así como entre 
diferentes fracciones del capital (la inmobiliaria y el resto); y la capacidad (económica, y sobre todo política) del Estado para desarrollar actividades y destinar recursos fiscales (Pírez, 2014), y de manera particular, las relaciones políticas que se definen coyunturalmente.

Sobre esa intervención estatal existen aportes relevantes que no se repetirán ${ }^{26}$. Se puede comenzar refiriendo que desde la economía política se consideró inicialmente que la intervención estatal estaba estructuralmente definida. Sin embargo, y debido tanto a las transformaciones tecnológicas (TIC) como a los cambios en las relaciones económicas, particularmente el fortalecimiento y predominio del capital financiero, algunas empresas capitalistas asumieron la producción de infraestructuras y servicios, y los estados cumplieron un papel facilitador de esa producción mercantil.

Desde los años cuarenta y hasta fines de los setenta del siglo Xx la mayor parte de los estados latinoamericanos aplicaron políticas de desarrollo económico de base industrial para el mercado interno. La producción de las infraestructuras quedó como responsabilidad estatal que encargó su construcción a empresas privadas conformando operaciones plenamente mercantiles (Blanlot, 1992; Pírez, 2000; Toledo, 2008).

Ese involucramiento estatal no implicó la desmercantilización de la urbanización. La mención que se ha hecho del papel estatal en la urbanización barrial en el AMBA, permite identificar su orientación al fortalecimiento de la demanda para la producción mercantil (generar solvencia), aún durante el predominio de una orientación desarrollista y de bienestar.

La intervención estatal en la prestación de los servicios urbanos es más compleja. Con la estatización de las empresas privadas de servicios, entre los años cuarenta y sesenta, se intentó una orientación universal, utilizando subsidios cruzados en cada servicio y subsidios directos a los usuarios de bajos recursos (Pírez, 2000; Toledo, 2008). Sin embargo, pese a la ampliación de coberturas que se produjo, y las postulaciones de universalidad, no se eliminó la exclusión de los servicios de parte importante de la población (Pírez, 2000).

La consecuencia fue el desarrollo de procesos sociales de desmercantilización, por medio de la autoproducción o bien por su movilización frente a los organismos estatales, particularmente de nivel municipal, para presionar por una mayor atención de esas necesidades.

Así, la urbanización popular incluyó los servicios, permitiendo su acceso con base en el esfuerzo de los usuarios necesitados, por lo general sin ampliar la redistribución. Esta modalidad, como se vio, no permite incluir a todos los servicios urbanos, lo que deja fuera a aquellos que requieren niveles de tecnología y de inversión que no se tienen. La evidencia sobre esos procesos de urbanización muestra que los servicios de agua y electricidad son los que más han sido producidos de manera socialmente desmercantilizada. Tanto en relación con la producción de las infraestructuras como con la prestación del servicio.
26 Entre otros, Jaramillo (1989), Pirez (2013b).

territarias 34

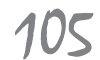


Esas infraestructuras se han basado predominantemente en conexiones clandestinas a las redes regulares, siempre que estas estuviesen en la cercanía de los asentamientos populares. Cuando no se daba esa condición aparecieron alternativas. En el caso del agua, algunas experiencias que mantienen el carácter de bienes colectivos con organizaciones no mercantiles como las cooperativas, realizan perforaciones $\mathrm{y}$ distribuyen el agua; o soluciones individuales con perforaciones, generalmente familiares, donde existen napas subterráneas accesibles. Lo mismo para la realización de pozos sépticos (Brunstein, 1988; Mutuberría, 2007; Pírez, 2000). La ausencia de red formal obligó, en algunos casos, a consumos mercantiles de mayor costo y, a veces, de menor calidad, desde la compra de agua embotellada, pasando por la compra privada de distribución de agua en camiones. De todas maneras, la producción individual del agua implica un retroceso respecto de la socialización de las condiciones de reproducción de la población, con pérdidas en la calidad del servicio, pérdidas económicas y pérdidas ambientales.

En la electricidad, la producción popular adoptó, por lo general, la forma de conexiones clandestinas a las redes formales, lo que produjo redes secundarias hasta las viviendas individuales. Estas conexiones presentan varios problemas, además de los costos de su producción, mala calidad (cortes, bajas de tensión, etcétera) e inseguridad para los usuarios, lo que también afecta a las redes formales.
La gestión estatal de los servicios urbanos estuvo fuertemente politizada, tanto en los niveles centrales como locales, condicionando la producción del hábitat urbano para los sectores populares (Duhau, 1998; Gilbert \& Ward, 1982; Hayata, 2010). El Estado, por lo general, respondió con comportamientos permisivos frente a la urbanización popular. Por ejemplo, en Bogotá, durante los años setenta, se permitió la expansión de la vivienda de bajos ingresos por medio de urbanizaciones piratas (Gilbert \& Ward, 1982); así como en Buenos Aires en los años ochenta se aceptó de manera implícita el consumo clandestino de los servicios (Pírez, 2000 y 2009).

La permisividad estatal frente a las irregularidades de la urbanización popular era parte de relaciones de dominación que inducían a establecer y mantener vínculos de clientela para el logro de los bienes urbanos; contribuía a descargar al Estado del peso de garantizar esos bienes para la población de bajos ingresos; por otra parte, esa producción informal contribuía a disminuir el costo de reproducción de la fuerza de trabajo, que era transferido a la población misma (Jaramillo, 2012). De todas formas, la permisividad no fue generalizada ni permanente. En algunos casos la autoproducción fue reprimida, sea como respuesta a presiones sobre los gobiernos (de empresas privadas, particulares afectados, etcétera) o contradicciones con otras definiciones de políticas estatales (con respecto a la propiedad privada, por ejemplo) (Gilbert \& Ward, 1982). 
La politización se observa también en la relación con las empresas estatales de servicio. Fue una constante el llamado uso político de las tarifas: si se mantenían bajas como si aumentaban, parecían estar más determinadas por criterios políticos que técnicos.

En síntesis, las políticas de "bienestar" en América Latina se movieron entre cierta satisfacción de la necesidad popular de ciudad, la permisividad de procesos populares de urbanización y la represión de invasiones de suelo o conexiones clandestinas de servicios. Se configuró una suerte de política implícita que permitía una limitada satisfacción de las necesidades de bienes urbanos a las familias de bajos recursos y, al mismo tiempo, contribuía a mantener la 'paz social' (Gilbert \& Ward, 1982; Hayata, 2010; Pírez, 2009).

Con la restructuración neoliberal y el cambio de orientación en las acciones estatales lo anterior se modificó: la transformación de las regulaciones (más que la desregulación) y las privatizaciones fueron dos procedimientos que contribuyeron a mercantilizar (o re-mercantilizar) la producción de los servicios (Pírez, 2013b). Igualmente importantes fueron los cambios en el apoyo al consumo. Por un lado, se dejaron sin efecto la mayor parte de las permisividades que existían para con los consumos clandestinos, llegando a su represión penal (Pírez, 2009). Por otro, la focalización generalizada de las políticas sociales significó el abandono de las tendencias universalistas, por lo menos en términos de su postulación, para aplicar apoyos financieros de manera particularizada a los sectores más vulnerables de la sociedad, debiendo los demás, aún en condiciones de pobreza, resolver el acceso a las infraestructuras y servicios de manera mercantil o por medio de la autoproducción. Las consecuencias fueron, por lo general, el empeoramiento de las condiciones de la calidad urbana de las familias excluidas del mercado.

\section{Elementos para continuar}

Las proposiciones del artículo se abren hacia tres cuestiones que son aquí solamente presentadas.

En relación con la noción de solvencia. Es preciso entenderla no como dualidad sino como posiciones polares en un gradiente, que depende de (a) los ingresos según su origen (ganancia, renta y salario e ingreso informal); (b) en relación con el salario, su versión directa y las prestaciones (salario indirecto) que dependen de tiempo y lugar; (c) los gastos para la reproducción, el sistema de precios (afectados por la inflación), las tarifas y los impuestos; y (d) las condiciones de clase, como puede ser la herencia o las calificaciones educacionales, que diferencia las capacidades de solvencia, además de las dos anteriores.

Sobre el pago de los servicios en la producción mercantil se presentan de manera inmediata dos preguntas: ¿Quién paga para sostener el servicio? ¿Cuál es el origen y recorrido (flujo) de los recursos que se aplican a esos pagos? La primera pregunta se puede contestar de tres formas: (a) La territarias 34

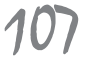


totalidad de las cargas (operación e inversión) atribuidas a los usuarios del servicio (plena mercantilización), todos los recursos necesarios salen del precio del servicio (tarifa). La significación de esa carga dependerá, tanto de su peso relativo como del sistema social de distribución de recursos. (b) Separa lo relativo al sostén económico de la operación o producción del servicio, de la inversión, encargando al Estado de esta última. Esto garantizaría la continuidad de las condiciones de la calidad urbana, socializando sus costos (desmercantilizar parte de la producción). (c) No cargar sobre los usuarios, o al menos una categoría de ellos, ninguna de las dos fases, en un proceso de plena desmercantilización. Esta respuesta combina dos cuestiones, la desmercantilización de los servicios y su universalidad. Una manera de desarrollar esto último es diferenciar los usuarios en el intento de identificar una frontera entre la solvencia (capacidad) y la insolvencia (incapacidad o extrema dificultad) para enfrentar económicamente los servicios. Planteada de esta forma la relación social del servicio, el actor que se hace cargo de la operación es un intermediario entre la decisión estatal de la prestación del servicio y los usuarios. Dicho de otra forma, es el nexo entre la aplicación de los recursos necesarios para el proceso de producción y el origen de esos recursos.

En relación con una perspectiva de derecho a la ciudad. En el contexto conceptual que se ha definido, el derecho a la ciudad se define por su contradicción con la mercantilización. La ciudad capitalista resulta de las tensiones entre los procesos de reproducción económica y los de reproducción social y, consecuentemente, entre sus ámbitos espaciales, que se manifiestan en las contradicciones entre el espacio urbano significado como bien de cambio o como bien de uso.

Como consecuencia, el derecho a la ciudad, entendido como derecho a la centralidad, implica la posibilidad de asentarse en el ámbito urbano de manera de poder gozar de esos bienes heterogéneos. Es decir, derecho al suelo urbano, a la vivienda, al transporte, a las infraestructuras urbanas, a los equipamientos urbanos y sociales, a sus servicios, etc. En este sentido, es evidente la preeminencia que tiene el acceso al suelo, como condición del conjunto de los bienes y procesos de la urbanización, de allí que se haya afirmado que "el acceso al suelo urbano constituye con frecuencia el factor decisivo de integración a la ciudad, la primera forma de reconocimiento de una plena ciudadanía" (Durand-Lasserve, 1997, p. 10). El derecho a la ciudad supone el derecho al lugar como ámbito particular de la vida social, tanto como derecho a los "satisfactores" (suelo, vivienda, servicios, etc.), como derecho a la centralidad: ser parte del conjunto de relaciones que hacen y renuevan la sociedad aglomerada (ciudad).

Ese derecho se basa en la contradicción que se da entre mercantilización y acceso que se define, históricamente, por la configuración de una demanda solvente subordinada al mercado y, por lo tanto, a las relaciones de reproducción del capital, frente a la existencia de procesos de 
desmercantilización que permitan, por lo menos parcialmente, el acceso al asentamiento en la ciudad capitalista (segregada, desigual, etc.) sometiendo a las familias, no ya al mercado, sino a relaciones del poder que lo legitima.

Como se ha mencionado, la mercantilización de la ciudad depende tanto de su producción capitalista como de la capacidad monetaria para acceder a ella. Esto significa que la posibilidad de la población (que puede ser entendida como derecho) a acceder a las condiciones de la urbanización está subordinada a su solvencia. A contrario sensu, la definición de la ciudad como derecho que sustituye su condición de mercancía reconoce la condición de ciudadanía de todo individuo o familia que forma parte de una aglomeración urbana.

Esa sustitución de la mercancía por el derecho requiere de la existencia de procesos que garanticen la efectiva desmercantilización. Esto significa que sus contradicciones deben ser resueltas social y políticamente, es decir, garantizar la posibilidad generalizada de acceder a esos bienes, reconocer el derecho al consumo desmercantilizado, al consumo no mercantil.

\section{Referencias}

Abramo, P. (2012). La ciudad informal comfusa: El mercado y la producción de la territorialidad urbana popular. En C. Salazar (Coord.), Irregular. Suelo y mercado en América Latina (pp. 85-124). México: El Colegio de México.
Azuela, A., \& Schteingart, M. (1990). Hábitat popular. En N. Clichevsky (Ed.), Construcción y administración de la ciudad latinoamericana (pp. 351-390). Buenos Aires: IIED-GEL.

Blanlot, V. (1992). La regulación del sector eléctrico: la experiencia chilena. En O. Muñoz (Ed.), Después de las privatizaciones. Hacia el Estado regulador (pp. 281-322). Santiago: CIEPLAN.

Bonduki, N. (2011). Origens da babitacao social no Brasil. São Paulo: Estacao Liberdade.

Brunstein, F. (1988). Saneamiento hídrico en el Gran Buenos Aires. Límite de la precariedad. En F. Brunstein (Ed.), Crisis y servicios públicos (pp. 5-41). Buenos Aires: CEUR.

Castel, R. (1997). La metamorfosis de la cuestión social. Una crónica del salario. Buenos Aires: Paidós.

Castells, M. (1995). La ciudad informacional. Tecnologias de la información, reestructuración económica y el proceso urbano. Madrid: Alianza Editorial.

Castro, M. \& Riofrío, G. (1997). La regularización de las barriadas: el caso de Villa El Salvador (Perú). En A. Azuela \& F. Tomas (Coords.), El acceso de los pobres al suelo urbano (pp. 45-88). México: CEMC-UNAM.

Connolly, P. (2012). La urbanización irregular y el orden urbano en la Zona Metropolitana del Valle de México de 1990 a 2005. En C. Salazar (Coord.), Irregular. Suelo y mercado en América Latina (pp. 379-425). México: El Colegio de México. territarios 34 109 
Connolly, P. (2013). La ciudad y el hábitat popular: paradigma latinoamericano. En B. Ramírez \& E. Pradilla (Comps.) Teoría sobre la ciudad en América Latina (pp.505-562, Vol. II). México: Universidad Autónoma Metropolitana.

Coulomb, R. \& Schteingart, M. (Coords.) (2006). Entre el Estado y el mercado. La vivienda en el México de hoy. México: UAM-A-Miguel Ángel Porrúa.

Cravino, C. (2006). Las villas de la ciudad. Mercado e informalidad urbana. Los Polvorines: Universidad Nacional de General Sarmiento.

Cravino, M. C. (Org.). (2012). Construyendo barrios. Transformaciones socioterritoriales a partir de los Programas Federales de Vivienda en el Área Metropolitana de Buenos Aires (2004-2006). Buenos Aires: Ediciones Ciccus-Universidad Nacional de General Sarmiento.

Cuervo, L. M. (1998). El régimen de servicios públicos domiciliarios. Primer Tiempo: Tecnocracias $=1$, Autonomía local=0. En vVAA, La investigación regional y urbana en Colombia. Desarrollo y territorio 1993-1997 (pp. 409-434, Tomo 1). Bogotá: Carlos Valencia Editores.

Duhau, E. (1998). Hábitat popular y política urbana. México: Miguel Ángel PorrúaUAM.

Duhau, E \& Giglia, A. (2008). Las reglas del desorden. Habitar la metrópoli. México: UAM-I, Siglo XXI.

Durand-Lasserve, A. (1997). Prólogo. En A. Azuela \& F. Tomas. El acceso de los pobres al suelo urbano (pp. 9-12). Mé- xico: Centro de Estudios Mexicanos y Centroamericanos, UNAM-IIS-PUEC.

Eibenschutz, R. \& Goya, C. (2009). Estudio de la integración urbana y social en la expansión reciente de las ciudades en México, 1996-2006: dimensión, caracteristicas y soluciones. México: SEDESOLUAM-X-Miguel Ángel Porrúa.

Esping-Andersen, G. (1993). Lostres mundos del Estado del Bienestar. Valencia: Edicions Alfons El Magnànim-Generalitat Valenciana-Diputació Provincial de València.

Gilbert, A. \& Ward, P. (1982). "Low-income housing and the state". En A. Gilbert, J. Hardoy \& Ramirez, R. (Eds.), Urbanization in Contemporary Latina America (pp. 79-127). New York: John Wiley and Sons.

Hayata, N. (2010). La ilusión de la participación comunitaria. Lucha y negociación en los barrios irregulares de Bogotá 1992-2003. Bogotá: Universidad del Externado.

Jaramillo, S. (1981). Producción de vivienda y capitalismo dependiente: el caso de Bogotá. Bogotá: CEDE-Uniandes.

Jaramillo, S. (1988). Crisis de los medios de consumo colectivo urbano y capitalismo periférico. En L. M. Cuervo, S. Jaramillo, J. I. González \& F. Rojas (Eds.), Economía politica de los servicios públicos. Una visión alternativa (pp. 15-37). Bogotá: CINEP.

Jaramillo, S. (2010). Hacia una teoría de la renta del suelo urbano. Bogotá: Universidad de los Andes. territarios 34 110 
Jaramillo, S. (2012). Urbanización informal: diagnósticos y políticas: Una revisión al debate latinoamericano para pensar líneas de acción actuales. En C. Salazar (Coord.). Irregular. Suelo y mercado en América Latina (pp. 33-84). México: El Colegio de México.

Kowarick, L. (1979). A espoliacao urbana. Río de Janeiro: Paz e Terra.

Lefebvre, H. (1969). El derecho a la ciudad. Barcelona: Editorial Península.

Mutuberría, V. (2007). Los servicios públicos urbanos como medios colectivos para la producción y reproducción de la vida de los sujetos en sociedad desde la perspectiva de la economía social. Análisis de experiencias de gestión colectiva en el Gran Buenos Aires. (Tesis de Maestría, Universidad Nacional de General Sarmiento, Buenos Aires, Argentina).

Offe, C. (1990). Las contradicciones del Estado del Bienestar. Madrid: Alianza.

Pírez, P. (1995). Actores sociales y gestión de la ciudad. Ciudades, 7(28), 8-14.

Pírez, P. (2000). Servicios urbanos y Equidad en América Latina. Un panorama con base en algunos casos. Serie Medio Ambiente y Desarrollo, 26. Santiago de Chile: CEPAL.

Pírez, P. (2009). Las sombras de la luz. Distribución eléctrica, configuración urbana y pobreza en la Región Metropolitana de Buenos Aires. Buenos Aires: Editorial de la Universidad de Buenos Aires.

Pírez, P. (2013a). Perspectivas latinoamericanas para el estudio de los servicios urbanos. Cuaderno Urbano, 14(14), 173-192.
Pírez, P. (2013b). Los servicios urbanos en América Latina. En B. R. Ramírez \& Emilio Pradilla (comp.). Teorías sobre la ciudad en América Latina (pp. 455504, Tomo II). México: UAM.

Pírez, P. (2014). La mercantilización de la urbanización. A propósito de los 'conjuntos urbanos' en México. Estudios Demográficosy Urbanos, 29(3)(87), 481-512.

Pradilla, E. (2009). Acumulación de capital y estructura territorial en América Latina: teoría e historia. En E. Pradilla (Comp.), Los territorios del neoliberalismo en América Latina (pp. 15-90). México: UAM-Porrúa.

Pradilla, E. (2013). La economía y las formas urbanas en América Latina. En B. R. Ramírez \& E. Pradilla Cobos (Comps.), Teorías sobre la ciudad en América Latina (pp. 169-238, Vol. 1). México: UAM.

Puebla, C. (2002). Del intervencionismo estatal a las estrategias facilitadoras. Cambios en la politica de vivienda en México. México: El Colegio de México.

Puebla, C. (2006). El Instituto del Fondo Nacional de la Vivienda para los Trabajadores (Infonavit). En R. Coulomb \& M. Schteingart (Coords.), Entre el Estado y el mercado. La vivienda en el México de hoy (pp. 193-238). México: UAM-A-Miguel Ángel Porrúa.

Rodríguez, A., \& Sugranyes, A. (Eds.). (2005). Los con techo. Un desafío para la politica de vivienda social. Santiago: Ediciones SUR.

Schteingart, M. (1989). Los productores del espacio habitable. Estado, empresa y socie- 
dad en la Ciudad de México. México: El Colegio de México.

Toledo, R. (2008). Infraestructura, metrópolis y medio ambiente: cuestiones de gobernabilidad y regulación a partir del caso de la Región Metropolitana de Sao Paulo. En G. Yáñez Warner, A. Orellana, Ó. Figueroa \& F. Arenas (Eds.), Ciudad, Poder, Gobernanza (pp. 431455). Santiago de Chile: Instituto de Estudios Urbanos y Territoriales.
Topalov, C. (1979). La urbanización capitalista. México: Edicol.

Torre, J. C., \& Pastoriza, E. (2002). La democratización del bienestar. En J.C. Torre (Dir.), Los años peronistas (19431955) (pp. 257-312). Buenos Aires: Sudamericana.

Yujnovsky, O. (1984). Claves politicas del problema habitacional argentino. 1955/1981. Buenos Aires: Grupo Editor Latinoamericano. 